\title{
Development of Learning Modules for Process Plant Operation
}

\section{Dr. Richard Turton P.E., West Virginia University}

Richard Turton is the WVU Bolton Professor and chair of the Department of Chemical and Biomedical Engineering at West Virginia University. He taught the senior design course for 29 years and is co-author of the textbook Analysis, Synthesis, and Design of Chemical Processes now in its 5th edition. He is also a co-author of the book "Chemical Process Equipment" with Joe Shaeiwitz on equipment design.

\section{Dr. Fernando V. Lima, West Virginia University}

Fernando V. Lima joined the faculty as an Assistant professor of Chemical Engineering at West Virginia University (WVU) in January 2013. He is now Associate Professor of Chemical Engineering since August, 2019. His research group at WVU focuses on the development and implementation of process systems engineering methods for process design and intensification, advanced control and state estimation, modular energy systems and sustainability. He received his B.S. degree from the University of São Paulo in 2003 and his Ph.D. from Tufts University in 2007, both in Chemical Engineering. Upon completion of his Ph.D., he was a research associate at the University of Wisconsin-Madison and a postdoctoral associate at the University of Minnesota. Dr. Lima has served as the AIChE Society Associate Editor for the American Control Conference (ACC) for five years (2013-2015, 2017-2018). He is also a guest editor for Special Issues of Processes and Industrial and Engineering Chemistry Research journals and member of the Editorial Boards of Journal of Process Control and Processes.

\section{Mr. Brent A. Bishop, West Virginia University}

Brent Bishop is a graduate of West Virginia University's (WVU) Benjamin M. Statler College of Engineering. In 2016, he earned a Bachelor of Science degree in Chemical Engineering with minors in Mathematics and Leadership Studies and is currently pursuing a $\mathrm{PhD}$ in Chemical Engineering. His thesis research focuses on the design and control of modular energy systems and he also provides leadership education as well as scenario-based learning about chemical processes to the chemical engineering department. 


\title{
Development of Learning Modules for Process Plant Operation
}

\author{
Richard Turton (presenter), Brent Bishop, and Fernando Lima
}

\section{Department of Chemical and Biomedical Engineering}

West Virginia University, Morgantown, WV 26508

\begin{abstract}
Advances in course content for the capstone design course in chemical engineering over the past 30 years have been very significant. Many of these advances have been facilitated by the increase in computing power now available to students through process simulators and other computational tools.

Today expectations for the capstone design project are much higher than they were 20 years ago. Such expectations include multiple case studies, sophisticated optimizations including process economics, and life-cycle and safety analyses. However, very few chemical engineering graduates work for design and construction companies and those employed in the process industry will more likely work in an operating facility. The senior capstone design project provides students an opportunity to bring different concepts taught throughout the curriculum into the design of a chemical process. The question is: how well does a rigorous chemical engineering undergraduate curriculum and the associated capstone design project prepare a student for their first 1-2 years in process plant operations? It likely requires an integration of the process design, process control, and process safety courses to explain the operation of chemical processes effectively.

The purpose of this paper is to discuss some of the approaches used by the authors to teach undergraduate students how chemical processes operate and to introduce a series of educational modules that address plant operation. The use of a "standard" steady-state simulator, the work horse of the capstone design course, is unhelpful in teaching about plant operations, rather a dynamic simulation of the process is required that possesses many of the features of the operating plant. Such features include the correct process dynamics, the control system, and safety features such as emergency relief valves and the appropriate digital logic to start and stop equipment. This approach naturally focuses on the level of information contained in a piping and instrument diagram (P\&ID) rather than the process flow diagram (PFD) that is used most frequently in the capstone design. To this end, the authors have developed a dynamic model of a styrene production process and then discuss several modules that illustrate normal and abnormal operations of the plant. These modules introduce typical control schemes for the start-up of a part of the plant, a shut-down procedure that an operator might use to mitigate an unwanted process condition, an emergency relief system used to protect the integrity of a piece of equipment, and several other scenarios. A video of one of the procedures will also be shown in the presentation to illustrate the pedagogy used to design the system and to show the subsequent operation of the system. These modules or scenarios could be implemented in any or all of the design, control and safety courses with good effect.
\end{abstract}




\section{Introduction}

In an ideal world, all undergraduate chemical engineering students would learn the basics of process design and steady-state optimization while supplementing their education with an internship or a co-op to gain real world experience before they begin their careers. Students would then leave their programs equipped with both a theoretical knowledge and a practical intuition of chemical processes. Unfortunately, this is not the experience most undergraduate students have in their programs and motivates the question: how can chemical engineering educators provide this practical intuition of chemical process operations in a classroom setting?

One method is to take a similar pedagogical approach as used in the design or classic controls courses. The concept of operating chemical processes is simply extended by using the same equations and no longer assuming steady state. This could work; however students gain an intuition about the dynamic equations, not the process itself. This approach to learning process dynamics is analogous to teaching a student a new language. The student memorizes the translations between languages rather than trying to directly understand the new language. It is easier to learn a language when a student is put into the setting where that language is used, i.e., an immersive learning environment. This same concept can be applied to chemical engineering.

This approach to education is referred to in the educational literature as "scenario-based learning" and originates from Lave and Wenger's theory of situated learning (Lave and Wenger, 1991). If students can experience scenarios about the content, they should more effectively learn and retain the information. Gott and Lesgold (2000) demonstrated this in their paper focusing on the training of Air Force technicians with two years of experience. The technicians were asked to complete twenty-five hours of scenario-based e-learning that consisted of multiple simulations of electrical equipment failures. In their conclusions, they found that the two-year technicians showed similar levels of expertise to technicians with ten years of experience. Thus, twenty-five hours of scenario-based learning translated to eight years of work expertise. This scenario-based learning approach using dynamic simulations of chemical processes should more closely result in the kind of practical intuition a student gains from an internship than a traditional lecture-based approach would.

Within the chemical engineering education literature there are examples of using case study approaches with dynamic simulators to help students meet the expectations and needs of practical engineering. For example, Bequette and Ogunnaike (2001) discuss the benefits of using dynamic simulation in advanced control classes and cite the work of Downs and Dross (1991) who support teaching process control by demonstrating important concepts through a case-study approach similar to the way that is done by the medical, legal, and business professions. Interestingly, at the recent AIChE Annual meeting in Orlando a student (Chem-E Sports Competition) competition was initiated whereby teams of students competed against each other to control a series of upsets in a distillation column by minimizing the economic penalty associated with the upsets. These scenarios were simulated on a dynamic simulator in a gaming environment. Mackenzie et al. (2001) discuss the use of a dynamic model, the Amoco Computer Simulation Model of a Resid Hydrotreater, in the senior design class. The simulator was used to show students many of the features of a large-scale industrial plant and to demonstrate, among 
other things, the start-up of the plant. They report that students' experiences were very positive and that students "enjoyed this industrial-based example of a chemical process giving them a real world experience with time and budgetary constraints." Komulainen et al (2012) discuss various experiences of using dynamic software in chemical engineering education. They note that "commercial dynamic simulation software allows students to interact with a realistic simulation of an actual process using a user interface that resembles a plant operator interface." They go on to describe their experiences using three dynamic models for a binary distillation column, a three-phase separator, and a two tank system. They concluded that dynamic simulation was very effective in teaching a wide variety of chemical engineering courses. Finally, Eizenberg et al (2006), discuss their experiences of combining dynamic simulation and HAZOP analysis in the process safety engineering course. Their approach allows a quantitative analysis of the behavior of a hydrocarbon oxidation in a semi batch reactor and illustrates the cause of a runaway reaction when various parameters are changed in their model.

In the current work, a full dynamic simulation of a chemical process forms the basis for a series of scenarios that are aimed at teaching students about the how and why certain control schemes are used and to provide a basis for a deeper understanding of how a chemical process works in the "real world."

\section{Process Description}

The process on which the various case studies/scenarios are based is the production of styrene from ethylbenzene. This is a fairly well studied process for which a base case simulation is available, Turton et al. (2018). The process flow diagram for this process is shown in Figure 1 and represents a reasonably straightforward process in which ethylbenzene is heated and mixed with high temperature steam and fed to a catalytic gas-phase reactor. The reaction is endothermic and to increase the single-pass conversion, the reactor effluent is heated prior to sending to a second reaction stage. The reactor effluent from the second reactor is cooled in a series of heat exchangers before entering a three phase separator in which the hydrogen-rich stream is sent overhead, the dense aqueous phase is sent for wastewater treatment and the organic phase is separated in two distillation columns to give the styrene product, toluene and benzene by-products, and an unused ethylbenzene that is recycled to the front end of the process.

A dynamic simulation of the styrene process was developed using the AVEVA SimCentral Simulation Platform. This platform allows easy transition from steady-state to a pressure-driven fluid-flow mode to a full dynamic pressure-driven simulation in a single simulation environment. Having one simulator that can smoothly transition between different simulation modes can be easier for undergraduate students who are new to dynamic simulators. Students are provided copies of the styrene PFD, P\&IDs, a process description, equipment specifications, and other pertinent details of the design case. Later in the learning process, students work with the dynamic simulator to implement new control systems and to observe the action of the process to changes in conditions that are investigated in the various learning scenarios discussed next. 


\section{Different Operating Scenarios}

As stated previously, the purpose of the different scenarios is to improve the understanding of how the process operates under off-design conditions. These conditions may occur routinely through changes in the environment, e.g., a change in cooling water or refrigerated water temperature due to changes in ambient conditions. Alternatively, they could be the result of abnormal or emergencies conditions. A list of the different scenarios considered is given in Table1. A brief description of each scenario is also given in the table. Although some of the scenarios are specific to the styrene process, many are generic and apply to most chemical processes.

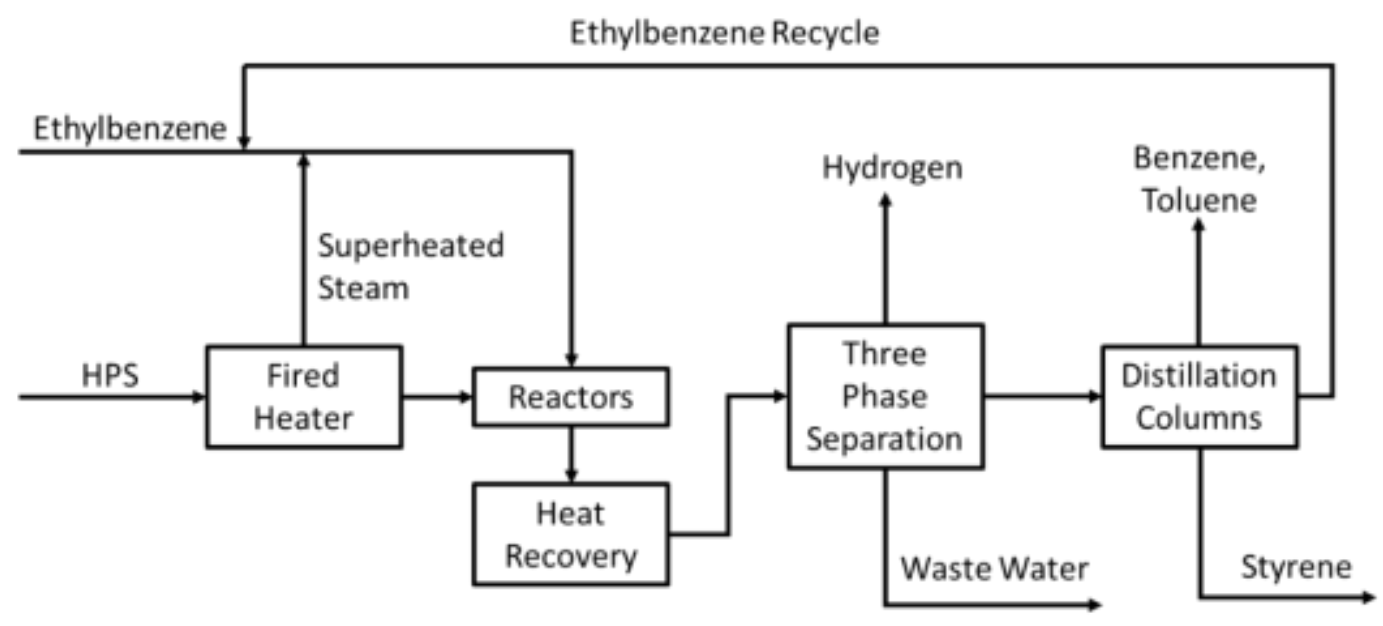

Figure 1: Block Flow Diagram for Styrene Process

The process by which each scenario is introduced to the student, the information provided, the in-class and out-of-class exercises, and the main points (take-aways) have been standardized into the following steps:

1. Process Description - the students are provided with the PFD (Figure 1) and a description of the process at the start of these exercises. However, additional process information relevant to the scenario being considered is included.

2. Scenario Description - this is a brief statement about the condition that gives rise to the scenario.

3. In-Class Activity - a short set of questions are given to the students that define what they are being asked to do. In order to stimulate class or group discussion, a set of prepared questions and answers are supplied to the instructors that enables them to guide the students through the thought process necessary to understand the physics of the problem, which may not always be straightforward. In addition, these questions test the students understanding of what a given piece or pieces of equipment actually do(es) in the process.

4. Student Activity - this activity involves running the scenario in the dynamic simulation and observing the effect of the equipment malfunction or change in operating conditions on the process. With the background information given during the in-class activities, students are expected to formulate a change that will minimize the effect given in the scenario or remedy 
the problem. This action is specific to the scenario and might be as simple as closing a valve that was inadvertently left open or implementing a new control scheme to prevent an explosion or another serious consequence.

Table 1: Different Scenarios/Case-studies for the Styrene Process

\begin{tabular}{|c|c|c|}
\hline $\begin{array}{l}\text { Scenario } \\
\text { Number }\end{array}$ & Scenario Title Description & $\begin{array}{l}\text { Brief Description of Scenario and Questions to } \\
\text { be answered }\end{array}$ \\
\hline & \multicolumn{2}{|r|}{ Generic Issues } \\
\hline 1 & Pump cavitation & $\begin{array}{l}\text { Excessive vibration, noise, and/or discharge } \\
\text { pressure fluctuation observed in the field } \\
\text { meaning that the pump may be cavitating. } \\
\text { What is the cause and how to fix the problem? } \\
\text { How to restart the pump. }\end{array}$ \\
\hline 2 & Surge control on a compressor & $\begin{array}{l}\text { Compressor observed to be operating near the } \\
\text { surge line - what are consequences and what } \\
\text { are the remedies }\end{array}$ \\
\hline 3 & $\begin{array}{l}\text { Change in atmospheric conditions } \\
\text { leading to a change in } \mathrm{cw} \\
\text { temperature }\end{array}$ & $\begin{array}{l}\text { Ambient conditions (temperature) changed due } \\
\text { to seasonal variations or prolonged period of } \\
\text { non-typical weather. What are the } \\
\text { consequences for the process? }\end{array}$ \\
\hline 4 & $\begin{array}{l}\text { Loss of flame in fired heater - } \\
\text { warm start-up of fired heater }\end{array}$ & $\begin{array}{l}\text { What is the correct start-up procedure for the } \\
\text { fired heater if there is a flame-out? }\end{array}$ \\
\hline 5 & $\begin{array}{l}\text { Scale-up or scale-down of a } \\
\text { distillation column }\end{array}$ & $\begin{array}{l}\text { If production increases or decreases, what are } \\
\text { the consequences for the separation systems? } \\
\text { Flooding, weeping, product quality control. }\end{array}$ \\
\hline 6 & $\begin{array}{l}\text { Unexplained pressure increase in } \\
\text { heat recovery unit }\end{array}$ & $\begin{array}{l}\text { Looks at diagnosing a process problem and } \\
\text { evaluating whether there is an instrument error } \\
\text { or if there is a true process change. }\end{array}$ \\
\hline 7 & $\begin{array}{l}\text { Fire detected by the ethylene feed } \\
\text { tank }\end{array}$ & $\begin{array}{l}\text { What safety systems should be in place to } \\
\text { protect the tank integrity and what shutdown } \\
\text { procedure should be implemented? }\end{array}$ \\
\hline \multirow[t]{2}{*}{8} & Loss of cooling in the plant & $\begin{array}{l}\text { What safety measures need to be in place to } \\
\text { deal with a loss-of-coolant accident (LOCA)? }\end{array}$ \\
\hline & \multicolumn{2}{|c|}{ Scenarios Specific to Styrene Process } \\
\hline 9 & $\begin{array}{l}\text { Compressor trip in styrene } \\
\text { column overhead line }\end{array}$ & $\begin{array}{l}\text { Leads to unwanted increase in styrene bottom } \\
\text { product temperature. }\end{array}$ \\
\hline 10 & $\begin{array}{l}\text { Reactor over-pressure due to open } \\
\text { steam by-pass line }\end{array}$ & $\begin{array}{l}\text { Consequence of over-pressurizing the styrene } \\
\text { reactor - how to protect reactor integrity. } \\
\text { Implementation of relief valve system. }\end{array}$ \\
\hline
\end{tabular}

5. Implementation of design changes in the simulation or an "operator" action and evaluation of such changes. Students implement their changes in the simulator and observe the scenario with their changes in place. Evaluation of the effectiveness of the change and additional refinements can be made 
6. In-class review of a "recommended" change or action available in a video format - a set of videos that explain each scenario and the "recommended" strategies to mitigate the consequences of the malfunction are provided and students watch these and compare their solutions to the ones recommended. Each video is typically 5 minutes or less in length. Discussion on each "solution" is encouraged.

In order to demonstrate these 6 steps, a more detailed explanation of Scenario 9 in Table 1 is given in Table 2 . The notes in Table 2 are mainly provided to help the instructor prompt appropriate discussions among the students. In this type of scenario-based problem, there is a significant amount of specific process knowledge and basic understanding of the process that the students must be aware of in order to pose reasonable and practical solutions. The amount of time that students are given to formulate solutions in the Student Activity section would depend on the scenario. For the compressor trip example, at least 20-30 minutes of discussion within groups would be required. However, the Formulate Solutions and Design Implementation phases for several scenarios could be posed as a problem set and then the whole troubleshooting exercise could be extended to a second class period with student groups implementing solutions to one or more scenarios and then observing the recommended solutions supplied on the videos.

\section{Student Feedback}

The scenario given in Table 2 was introduced as an exercise for a group of eight seniors currently taking the senior capstone design course. This and the other scenarios will be used in an upcoming elective course next year that will cover dynamic simulation of chemical processes. However, these scenarios can be used in a variety of courses including process control, senior capstone design, and process safety. The feedback from the students is summarized in Tables 3 and 4 and was obtained after about a 1 hour discussion and demonstration. 
Table 2: Compressor Trip on Styrene Overhead Line

Process Description: The styrene column (T-401) is a packed column that is used for separating the ethylbenzene reactant from the styrene monomer product. Because styrene monomer begins to undergo a rapid, exothermic polymerization at $123^{\circ} \mathrm{C}, \mathrm{T}-401$ must be operated under vacuum conditions to ensure the bottoms styrene product remains below this temperature. To do this, a variable speed compressor (C-402) is used to regulate the pressure in the reflux drum (V-402) by pulling non-condensable-gas out of the drum. A PFD (Figure 1) is provided below with the basic control scheme used for this tower. A P\&ID is also provided for the Styrene Column as Figure 2.

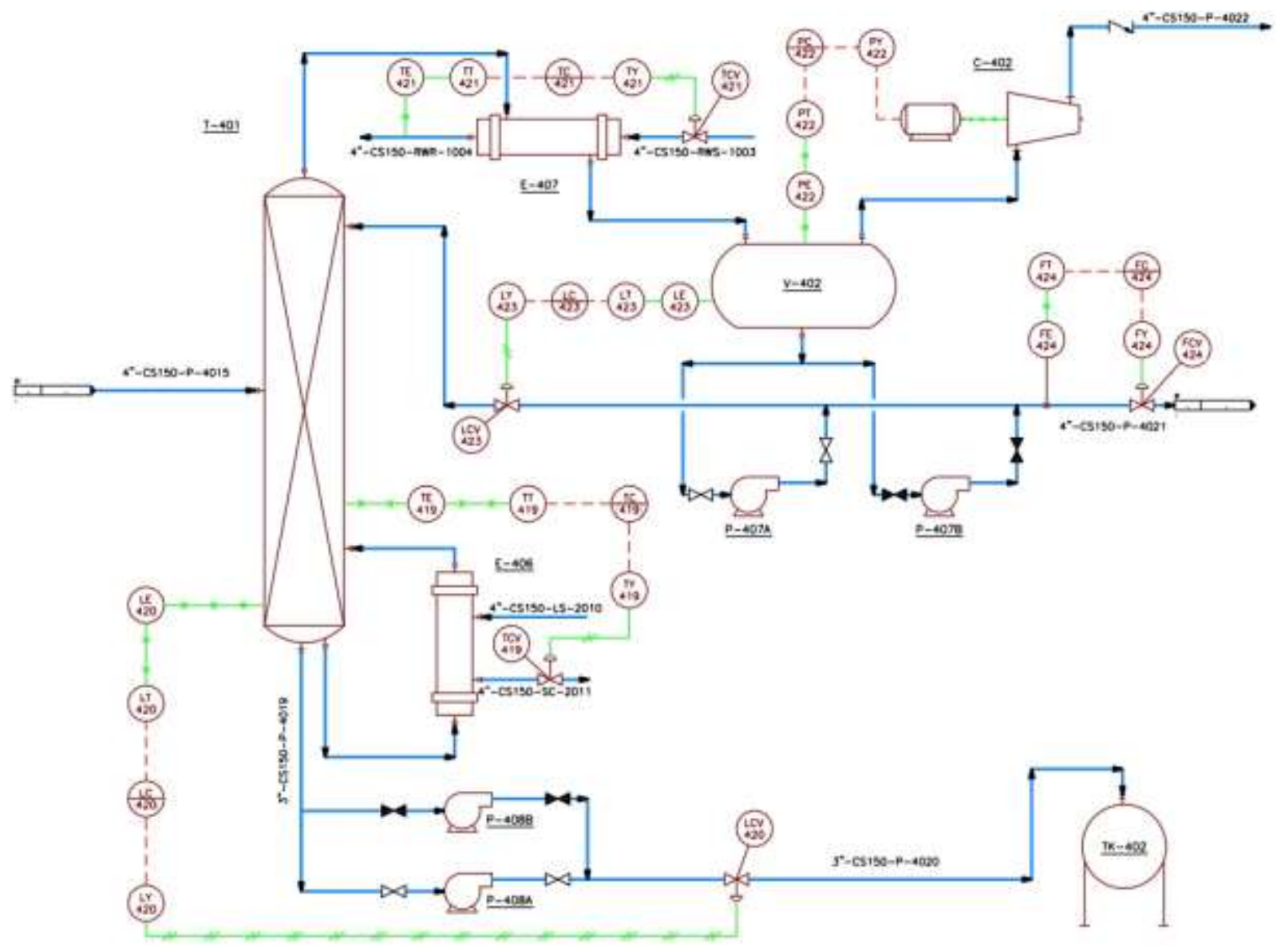

Figure 2: Piping and Instrument Diagram for Styrene Column

Scenario Description: During normal operation, C-402 begins to vibrate to a point where the automated safety system trips and shuts the compressor off to prevent equipment damage.

\section{In-Class Activity:}

Answer the following questions (assuming that restarting the compressor has been tried and has failed):

a. How do you expect T-401 to react to this change in process operation?

b. How do you expect the basic control layer to respond to this change in process operation?

Key prompts for instructors to ask students: 
1 (a) How do you expect T-401 to react to this change in process operation?

Q: What is the process purpose of the compressor (C-402)?

A: The compressor removes the non-condensable gases from the reflux drum and thus maintains the drum at vacuum conditions. Note: without non-condensables, the pressure at the top of the column can be controlled by controlling the process temperature in the condenser.

Q: Why are there non-condensable gases in the reflux drum?

A: Because the column operates at vacuum and air will be sucked into the equipment through flanges, etc.

Q: What happens when the compressor is shut down?

A: The non-condensable gases cannot be removed from the drum.

$\mathrm{Q}: \quad$ If the non-condensable gases are not removed what happens?

A: The pressure in the column starts to rise.

Q: How does an increase in pressure affect the operation of the column - especially in terms of the top and bottom products?

A: The pressure increases everywhere in the column and thus the top and bottom temperatures increase (because of VLE).

Q: What might be the effect of this pressure and temperature increase in the column?

A: The bottom styrene product may exceed $123^{\circ} \mathrm{C}$ and spontaneous polymerization would occur leading to a possible explosion (due to the exothermic polymerization reaction) and massive fouling at the bottom of the column.

Key prompts for instructors to ask students

1 (b) How do you expect the basic control layer to respond to this change in process operation? A P\&ID for the styrene tower is provided to students as Figure 2.

Consider the top of the column (Figure 2)

Q: What is the purpose of LCV 423 ?

A: This valve maintains the level of liquid product in V-401 by adjusting the reflux flowrate.

Q: What is the purpose of FCV 424?

A: This valve maintains the ethylbenzene product flow rate from $\mathrm{V}-402$.

Q: What is the purpose of TCV421?

A: This valve regulates the flow of refrigerated water to E-407 to maintain the exit temperature of the rw stream from the exchanger. This essentially controls the duty of E407.

Q: Do any of the above control valves help regulate the pressure of the column IF C-402 is tripped?

A: No - pressure is unregulated if compressor is tripped.

Consider the bottom of the column (Figure 2)

Q: What is the purpose of LCV 420 ?

A: This valve maintains the level of liquid styrene product in the column sump.

Q: What is the purpose of TCV 419?

A: The quality of the bottom styrene product is inferred by the temperature on a tray near the bottom of the column. The condensate flowrate is controlled using the temperature signal from the column tray. The level of condensate in the vertical thermosiphon reboiler's 
will adjust based on the exit flowrate and this regulates the amount of heat transfer taking place in the reboiler.

Q: Do any of the control valves at the bottom of the column help regulate the pressure of the column if C-402 is tripped?

A: No - pressure is unregulated if compressor is tripped.

Q: Do any of the control valves at the bottom of the column help regulate the temperature at the bottom of the column.

A: Yes - the condensate level control regulates the heat input at the bottom of the column and thus will affect the bottom temperature. This control loop may be sufficient to stop the styrene reaching the polymerization temperature.

\section{Student Activity}

1. Run the "Compressor Trip Scenario" simulation and observe the dynamics of the column. The results from the simulator are shown in the Figure 2.

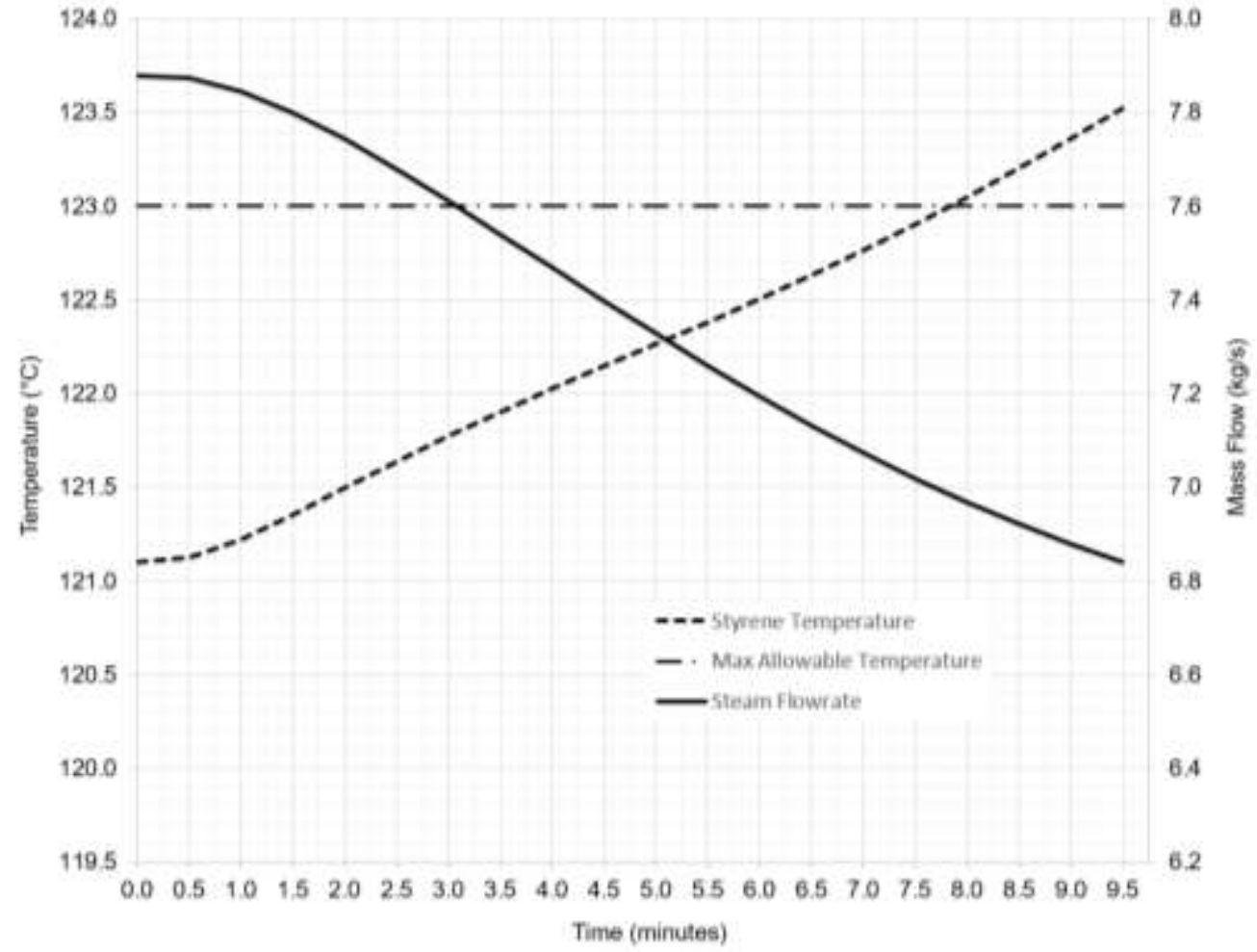

Figure 2: Response of styrene column bottom product temperature and reboiler steam rate to a trip of the compressor in the overhead line.

Q: Did the column and control system react the way you expected?

A: Yes, the steam rate was reduced in response to an increase in temperature in the column but the bottom of the column still exceeded the polymerization temperature.

Q: What additional control layer(s) is(are) required to ensure the safe operation of this unit? - Input from instructor on the different levels/layers of control typically used in a chemical plant is added here.

A: Students formulate solutions 


\section{Design Implementation}

Implement suggestions from Student Activities and rerun the simulator to show the response of the styrene column to the compressor trip. If the polymerization temperature is not exceeded then the solution is considered acceptable.

The Figure 3 shows an acceptable solution as a result of adding a second level of control.

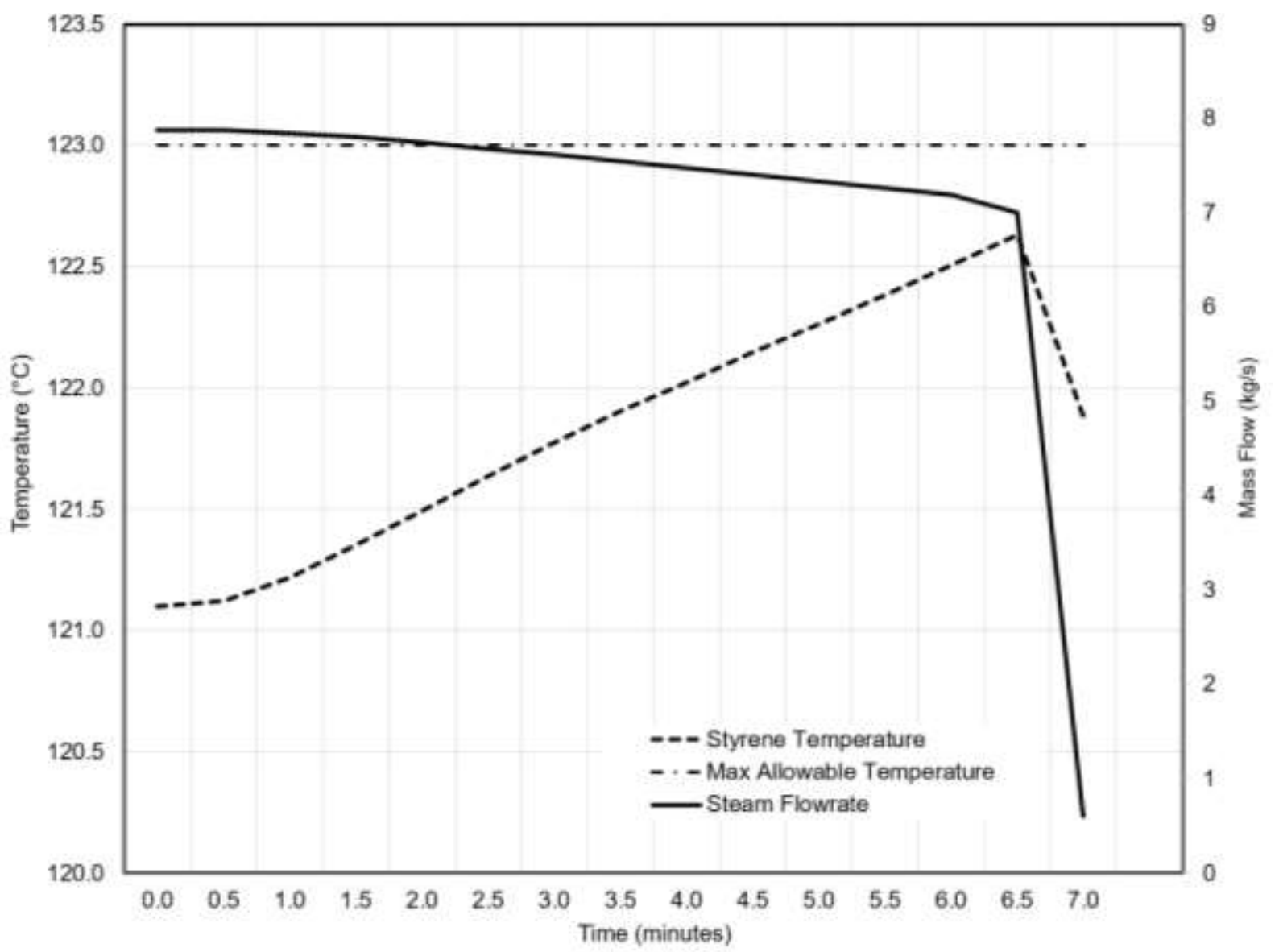

Figure 3: An acceptable response for the styrene column bottom product temperature by the addition of a secondary control loop.

\section{Review}

Students observe a video on the scenario and discuss alternative options - video will be shown during the oral presentation associated with this paper. 
Table 3: Summary of student feedback when asked how an activity involving process dynamics could help supplement other classes in their program.

\begin{tabular}{|c|c|c|}
\hline Question & Response & Specific Student Comments \\
\hline $\begin{array}{l}\text { Did this scenario provide you } \\
\text { a better understanding of } \\
\text { controlling chemical } \\
\text { processes? If so, in what } \\
\text { ways? }\end{array}$ & $\begin{array}{l}\text { All students believed this } \\
\text { activity gave them a better } \\
\text { understanding of controlling } \\
\text { chemical processes. }\end{array}$ & $\begin{array}{l}\text { "We only see the steady state } \\
\text { solution in our classes. In } \\
\text { industry (where } 90 \% \text { of us are } \\
\text { going) you have to solve } \\
\text { transient problems." } \\
\text { "I never had a good } \\
\text { understanding [until now] of } \\
\text { how multiple controllers } \\
\text { interact to maintain a } \\
\text { process." }\end{array}$ \\
\hline $\begin{array}{l}\text { Did this scenario provide you } \\
\text { a better understanding of } \\
\text { chemical process safety? If } \\
\text { so, in what ways? }\end{array}$ & $\begin{array}{l}\text { All students believed this } \\
\text { activity gave them a better } \\
\text { understanding of chemical } \\
\text { process safety. }\end{array}$ & $\begin{array}{l}\text { "[The activity] let us think } \\
\text { through the safety concerns } \\
\text { before executing it in the } \\
\text { process." } \\
\text { "[The scenario] helped } \\
\text { consider all the different } \\
\text { layers of safety and how they } \\
\text { regulate for safety." }\end{array}$ \\
\hline $\begin{array}{l}\text { Did this scenario provide you } \\
\text { a better understanding of } \\
\text { chemical process design? If } \\
\text { so, in what ways? }\end{array}$ & $\begin{array}{l}\text { All students believed this } \\
\text { activity gave them a better } \\
\text { understanding of chemical } \\
\text { process design. }\end{array}$ & $\begin{array}{l}\text { "We have a basic } \\
\text { understanding of simulations } \\
\text { now, but this shows more } \\
\text { layers of how and why certain } \\
\text { designs are chosen." } \\
\text { "[The activity] highlighted } \\
\text { some process control design } \\
\text { and how it is coupled with } \\
\text { normal design." }\end{array}$ \\
\hline
\end{tabular}

The results shown in Table 3, indicate that this scenario could fit in any of the three previously mentioned courses and that students' understanding of controls, safety and design increased. Table 4 indicates that students' participation in the "scenario experience" was both enjoyable and helpful and gave them an insight into "real-life" issues that transpire in chemical plants. The authors believe that having the suite of scenarios available will broaden these insights and provide a set of valuable case studies to help students transition from college to industry. 
Table 4: Summary of student feedback when asked about the scenario/activity itself.

\begin{tabular}{|l|l|}
\hline \multicolumn{1}{|c|}{ Question } & \multicolumn{1}{|c|}{ Specific Student Comments } \\
\hline $\begin{array}{l}\text { Wescribe your experience with the scenario. } \\
\text { helpful? }\end{array}$ & $\begin{array}{l}\text { "Extremely helpful. This gives a 'real-life' } \\
\text { approach to how equipment works and why. } \\
\text { This feels more like what most of us will be } \\
\text { doing on the job." } \\
\text { "I enjoyed it. Walking through step by step } \\
\text { was a great way to show why there are seven } \\
\text { layers of protection." } \\
\text { "Helpful: the plots and videos showing the } \\
\text { times. Unhelpful: Not crucial, but a lack of } \\
\text { understanding of how unsteady state } \\
\text { simulations are built." }\end{array}$ \\
\hline $\begin{array}{l}\text { What could have been done to improve the } \\
\text { scenario? }\end{array}$ & $\begin{array}{l}\text { "Obviously, having made the simulation } \\
\text { would be better for understanding what's } \\
\text { going on. This was a good way to present } \\
\text { this." }\end{array}$ \\
$\begin{array}{l}\text { "I think taking this class without controls } \\
\text { would be very difficult." }\end{array}$ \\
"I think reiterating a few of the important \\
aspects of the process."
\end{tabular}

\section{Summary}

A series of ten scenarios based on the ethylbenzene to styrene process were introduced to help deepen and broaden students' understanding of how chemical plants operate and respond to different stimuli and changes in operating conditions. A six-step procedure was presented to introduce the scenarios, explain the particular set of circumstances that lead to the scenario, and guide students through an understanding of the important issues in play and lead them to potential solutions to mitigate the effects of the process changes. A detailed description of one 
scenario is given for the case of a compressor failure in the overhead line of the styrene column. Student feedback and comments on this scenario were positive and indicate that exposure to scenarios like this one would be of benefit in the process design, process safety, and process control courses.

\section{Acknowledgements}

The authors gratefully acknowledge the financial support from AVEVA.

\section{References}

Bequette, B.W. and B.A. Ogunnaike, Chemical Process Control Education and Practice, Eye on Education, IEEE Control Systems Magazine, April, 10-17, 2001

Eizenberg, S., Shacham, M., and N. Brauner, Combining HAZOP with dynamic simulation Applications for safety education, Jnl. Loss Prevention in the Process Industries, 19, 754-761 (2006)

Gott, S. P. and A. M. Lesgold Competence in the workplace: How cognitive performance models and situated instruction can accelerate skill acquisition, In R. Glaser (Ed.), Advances in instructional psychology: Educational design and cognitive science, Vol. 5 (p. 239-327).

Lawrence Erlbaum Associates Publishers. (2000).

Komulainen, T.M., Enemark-Rasmussen, R., Sin, G., Fletcher, J.P., and D. Cameron, Experience on dynamic simulation software in chemical engineering education, Education for Chemical Engineers, 7, e153-e162 (2012)

Lave, J. and E. Wenger, Situated Learning: Legitimate Peripheral Participation, Cambridge University Press, Cambridge (1991)

Mackenzie, J.G., Earl, W.B., Allen, R.M., and I.A. Gilmour, Amoco Computer Simulation in Chemical Engineering, Jnl. Engineering Education, July, 331-345, 2001

Turton, R., Shaeiwitz, J.A., Bhattacharyya, D., and W.B. Whiting, Analysis, Synthesis, and Design of Chemical Processes, $5^{\text {th }}$ ed., Prentice Hall, Boston (2018) 